\title{
A Combined Scheme for Controlling GSM Network Calls Congestion
}

\author{
Alarape Moshood Alabi \\ Department of Computer Science \\ Federal Polytechnic, Bida, \\ Nigeria.
}

\author{
Akinwale Adio Taofiki \\ Department of Computer Science \\ University of Agriculture, Abeokuta, \\ Nigeria.
}

\author{
Folorunso Olusegun \\ Department of Computer Science, \\ University of Agriculture, Abeokuta, \\ Nigeria.
}

\begin{abstract}
Network congestion and signal quality degradation are the major problems of the Global System for Mobile communication (GSM) most especially as the number of customers increases. They are issues that constantly and continuously demand for further researches to improve network performance. Congestion in various systems has always been tackled with various attempts, all of which falls in either the congestion avoidance category or congestion management category. Congestion avoidance has however been adjudged the best scheme for controlling network congestion and this is the approach employed in this research work. The conventional GSM network calls congestion control methods such as Token Bank, Automatic Call Gapping among which Call Admission Control (CAC) is the best, was selected for this work. Dynamic load balancing technique was combined with CAC to re-route calls that would have been dropped to another less busy cell within the Base Station Controller (BSC) area. Dijkstra shortest path algorithm was used to find the shortest route to which calls can be transferred among the collocated base station cells. The combined algorithms were implemented on JAVA platform using real life call data record (CDR) collected from Globacom Nigeria Limited. New Call Blocking and Handoff Call Dropping Probabilities (NCBP and HCDP) were used to measure the performance results. The two probabilities were computed for both CAC only and the combined scheme. The results obtained showed that there is significant reduction in the values of both NCBP and HCDP by $71.43 \%$ and $100 \%$ respectively, of cells considered for the new combined scheme when compared with that of the CAC only. This indicates that the new scheme has further reduced the values of the NCBP and HCDP which enabled the cells to accommodate more calls thereby increasing the efficiency of the network performance.
\end{abstract}

\section{General Terms}

Network System Performance Management

\section{Keywords}

Congestion control, Call Admission Control, Load Balancing, NCBP, HCDP.

\section{INTRODUCTION}

The Global System for Mobile (GSM) communication has become a household term in our present world. This is due to the fact that communication in the life of man is so important and the use of the GSM network is not being limited to the rich alone but to all human beings be it rich, poor, old or young. This accounts for the ever-growing demand for GSM communications by people in the real sense of it as reported by the GSM Association which could make congestion inevitable [1]. The problem of network congestion is a network managerial issue that affects the quality of service (QoS) rendered by a network, apart from the fact that overutilization of a node in a network can lead to resources' short span or malfunctioning. Therefore congestion control is of utmost importance for the sustainability of the system and the development of a congestion control measure in this system should be a good effort in the right direction.

Several attempts had been made to forestall and manage the congestion in mobile networks like the GSM network which includes channel borrowing, cell-splitting, cell sectoring, development of micro-cells, dynamic channel allocation and deployment of soft handover schemes [2],[3],[4]. The techniques of controlling congestion employed so far in all systems have always in a general view, being focused on two principles. These principles are either to reject excessive traffic to prevent overload from occurring or diverting excess load if overload occurs. All the proposed techniques in the literatures had therefore been centered on these two principles. Attempt is made to use a combined scheme consisting of load balancing technique with a known efficient Call Admission Control (CAC) scheme in order to reduce the rate of network congestion and signal quality degradation

\section{LITERATURE REVIEW}

Load balancing as a system performance management technique had been applied in so many areas and to several systems in order to stabilize them. It had been applied to the assignment of tasks to processor in a multiprocessing computing environment. [5],[6]. Other areas of application of load balance include database state machine [7], robotic control system, [8] homogeneous and heterogeneous distributed system, managing peer-to-peer system $[9],[10],[11],[12]$ and channel sharing scheme in mobile networks [13], [14],[15],[16],[17],[12],[18],[19],[20],[21],[22],[23],[24].

In a more specific term with regard to calls as the traffic load, there exists various techniques of call congestion control among which are the Automatic Call Gapping (ACG) and the Token Bank (TB) [25]. The idea of the Automatic Call Gapping (ACG) is to reduce call attempt rate by allowing only one call attempt per a specified gap interval. This call attempt reduction occurs when the ACG mechanism is activated due to congestion and last for specified gap duration; possibly the congestion period. The Token Bank (TB) on the other hand is used for input regulation to protect an entity from becoming overloaded. It uses the parameters of token bank capacity C and the token bank rate $\lambda$. Tokens are generated periodically by an infinite source at a rate $\lambda$ into the bank. The token bank is associated with each source that generates call requests and when the token bank is full, then tokens are blocked and lost. 
If the TB is not empty then a call request is passed and a token is removed from the TB, otherwise the call request is dropped [25],[26].

Another most important and widely accepted existing technique of controlling congestion in GSM network is the Call Admission Control (CAC). It is a provisioning strategy used to limit the number of call connections into the networks in order to reduce the network congestion, call dropping and provide the desired Quality of Service (QoS) to users of the network [27],[28]. [29] proposed a scheme that combined admission control with Bandwidth adaptation to enhance the QoS provisioning. The scheme blocked a new call if the number of ongoing calls is greater than or equal to a stated threshold value or there is no bandwidth available in the given cell to accommodate the new call. However the incoming handoff calls is prioritized regardless of the number of ongoing calls or its requested bandwidth and if necessary bandwidth adaptation is performed. Their results showed that the handoff call dropping probability (HCDP) is near zero (i.e. 0.00208 ) and the new call blocking probability (NCBP) is greatly reduced.

The proposed congestion control scheme of [30] uses the buffer management technique to accept handoff calls temporarily in case there is no free channel to reduce the HCDP under the notion of guard channel principle. Their scheme blocked incoming calls when there is no free channel. The work of [31] was very similar to that of [29]. They combined bandwidth reallocation policy with adaptive call admission control. The significant difference between the two is that in the work of [31]; the bandwidth of all the ongoing calls are adjusted on the arrival of any incoming calls or at the completion of an ongoing call. The bandwidth is either degraded to accommodate new calls or upgraded in the event of service departure to enhance call services. Their scheme was proposed for cellular multimedia services and was combined with load balancing in this work.

\section{DESIGN METHODOLOGY}

The Combined Scheme was designed to incorporate a known Adaptive Call Admission Control (CAC) scheme of [31], and a load balancing strategy to further minimize the New Call Blocking Probability (NCBP) and the Handoff Call Dropping Probability (HCDP). The input to the system (i.e. calls) is made to pass through the CAC part of the combined scheme where calls are either rejected or accepted based on bandwidth availability which depends on the condition of the network system.

The first part of the CAC scheme which implemented the work of [31] which contains three (3) algorithms, namely: the Adaptive CAC (Ad_CAC), the UpgradeBW and the DegradeBW algorithms as shown in figures $1-3$ below.

The Adaptive CAC dynamically control the admission of calls in the network system by setting and resetting the bandwidth of the network to a level strong enough to sustain the processing of calls. It triggers the DegradeBW algorithm in an event of accepted call and the UpgradeBW algorithm when there is an outgoing handoff call or a call completion in the given cell.
The second part is the load balancing section illustrated as part of figure 4 in form of algorithm and its flowchart is depicted in figure 5 which has three phases of information policy, selection policy and the migration policy as usual for all load balancing strategy. The selection policy of the combined scheme proposed uses an implementation of Dijkstra shortest path algorithm [32] to find the most suitable BTS (or cell) to transfer call to. The suitability here refers to the closest cell to the source.

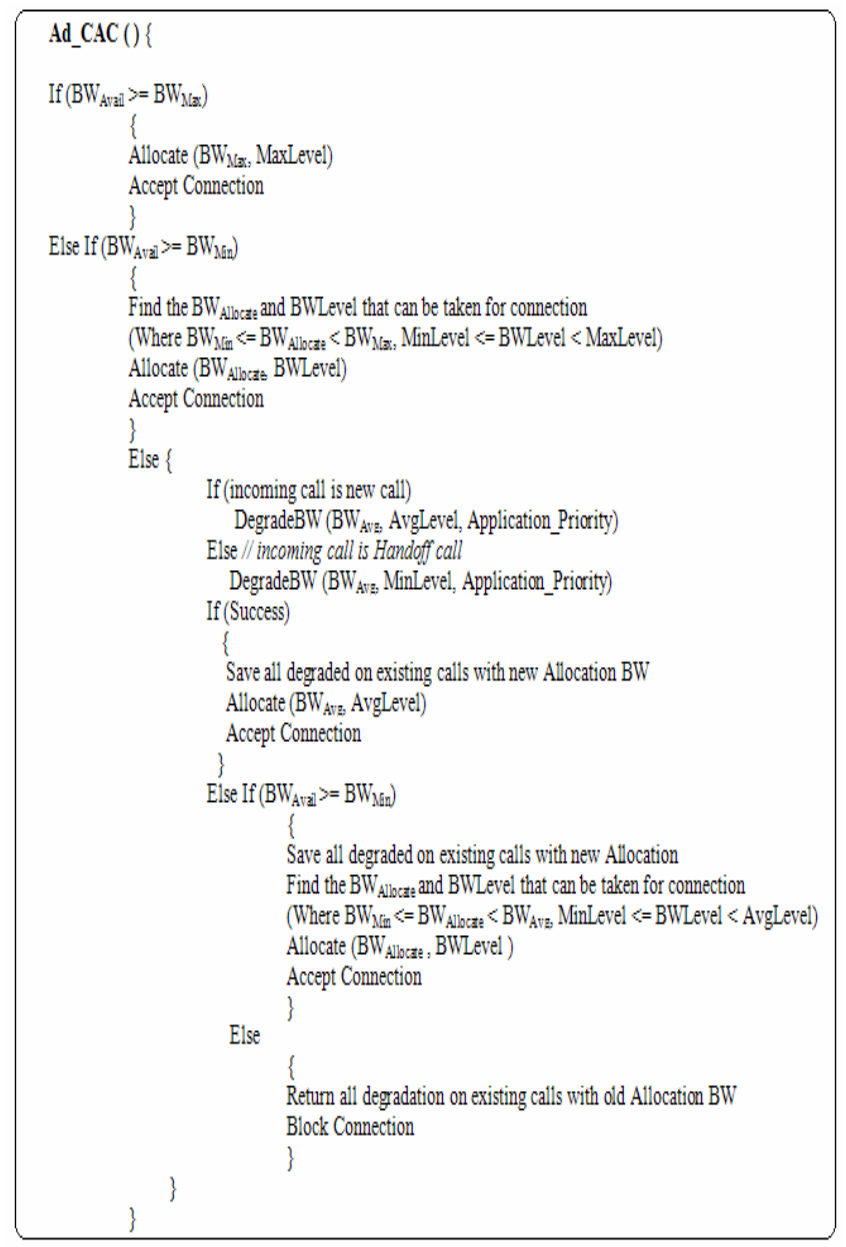

Fig 1: Algorithm for the Adaptive Call Admission Control (Ad_CAC) Scheme of Sanabani et al (2006) 


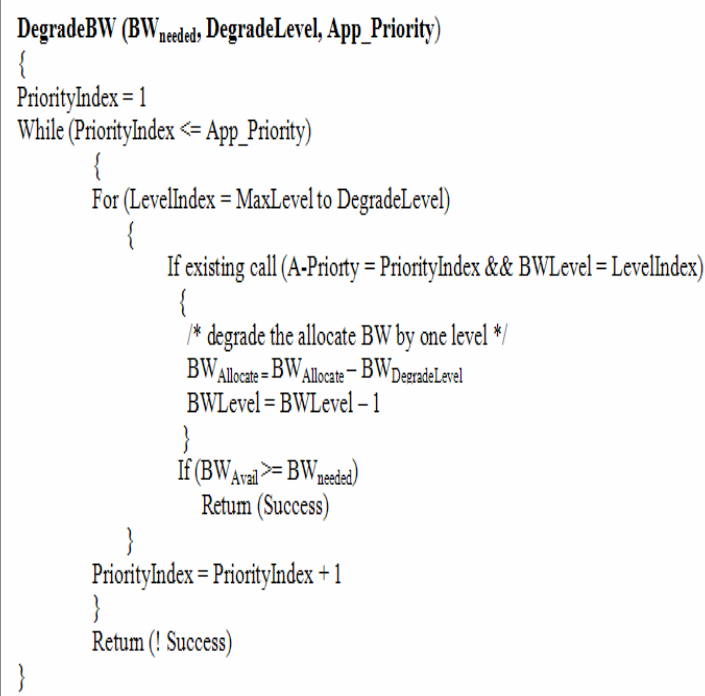

Fig 2: Algorithm for Degrade Bandwidth of Sanabani et al (2006)

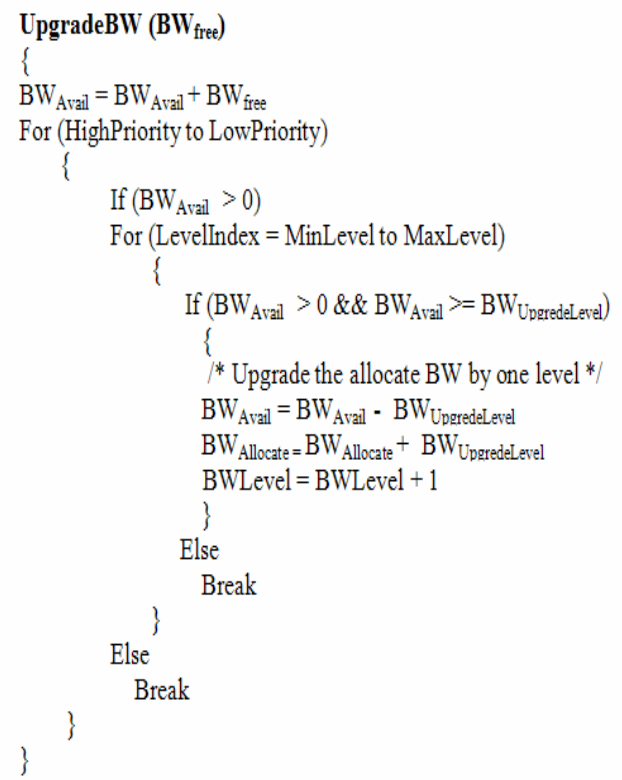

Fig 3: Algorithm for Upgrade Bandwidth of Sanabani et al (2006)

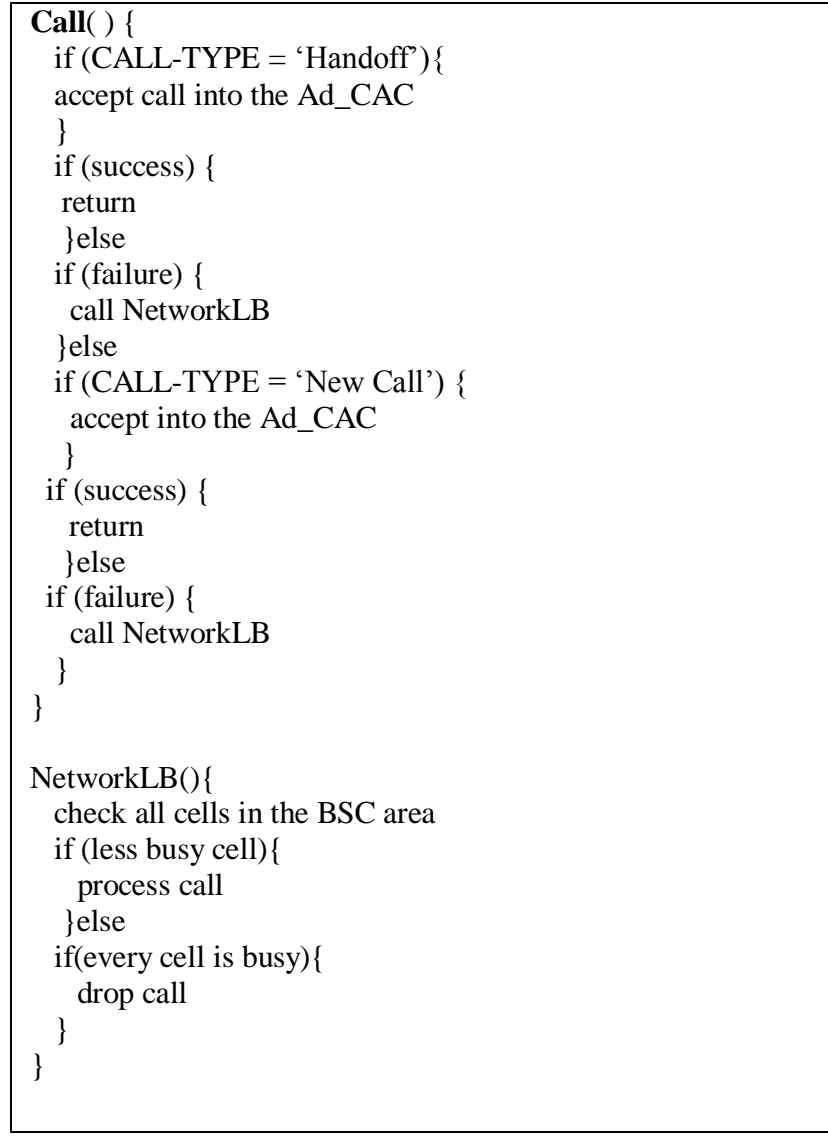

Fig 4: The Combined Scheme algorithm

\section{SYSTEM IMPLEMENTATION}

The combined scheme was implemented on JAVA platform. The input to the simulation experiments was obtained through real life network sample data collected from Globacom Nigeria Limited, Victoria Island, Lagos - Nigeria. A group algorithm and programming (GAP) package was used to analyze the data collected with the maximum and minimum call durations of 800 and 0 seconds respectively were incorporated into the JAVA program which then generated similar data randomly for processing. Other input data variables (e.g. inter arrival times of calls) were generated randomly using Java random number generator. A thousand (1000) calls were simulated for each cell in each BSC area and load balancing is done within each Base Station Controller (BSC) comprises of seven (7) cells. This was conducted using two BSCs in the simulation. 


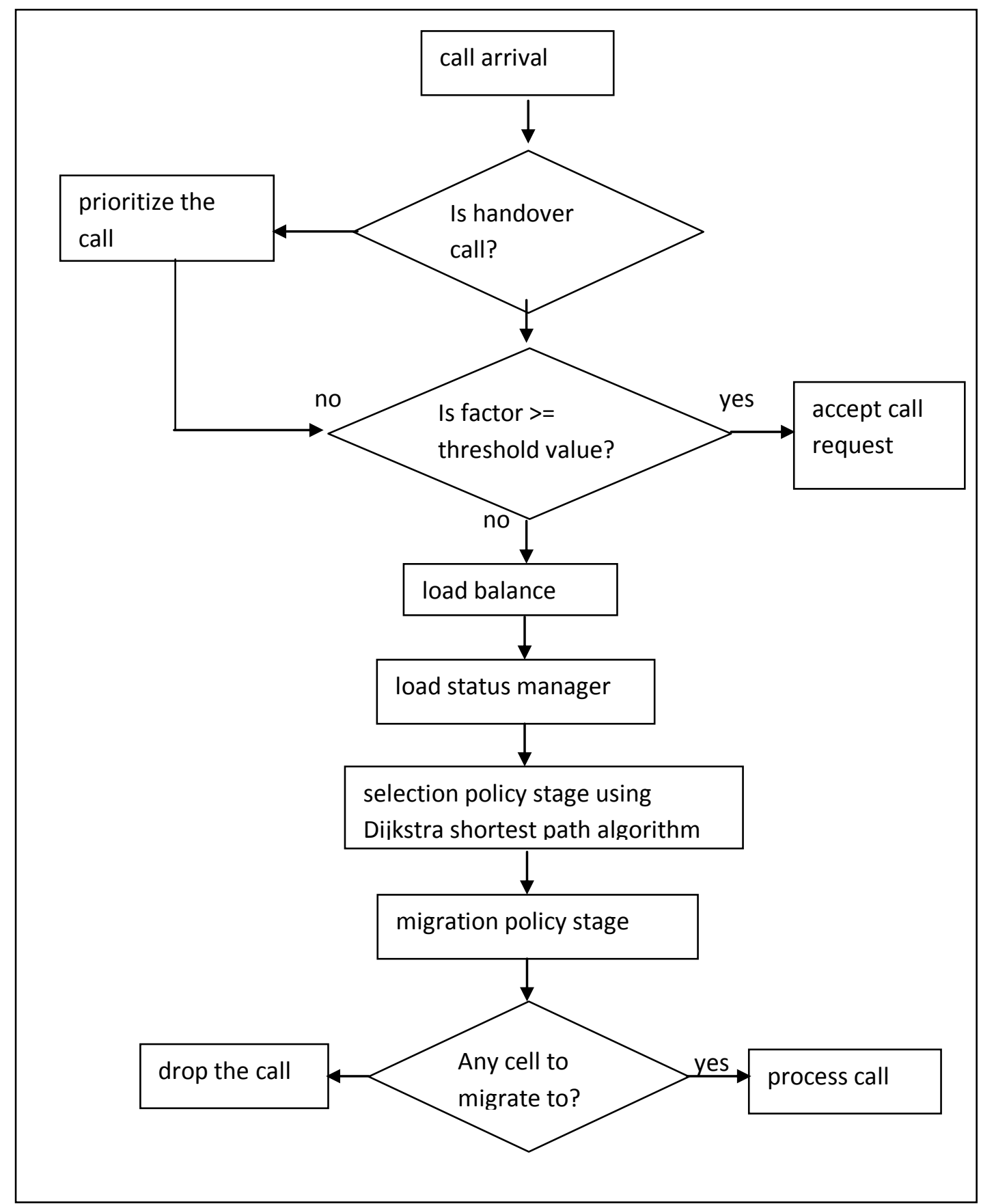

Fig 5: The Flowchart of Combined Scheme

\section{RESULTS OBTAINED}

There are two (2) sets of results from the implementation of the design. The first result was obtained from the CAC only scheme while the second was from the combined scheme. The results incorporated the computation of the New Call Blocking Probability (NCBP) and the Handoff Call Dropping Probability (HCDP) in which comparison was made between the two sets of results.

\section{PERFORMANCE EVALUATION}

The simulation results showed that the NCBP in the two (2) schemes are very close, although the new combined scheme still performed better in several cells than the CAC only scheme. The HCDP was greatly reduced with the use of the combined scheme when compared with that of the CAC only scheme. Figures 6a-d illustrate the new call blocking probability of [31] and combined scheme for BSC at step 0 and 1 in run 1 and 2 while figures $7 \mathrm{a}-\mathrm{d}$ describe hand off call probability of [31] and combined scheme for BSC at step 0 and 1 in run 1 and 2. 


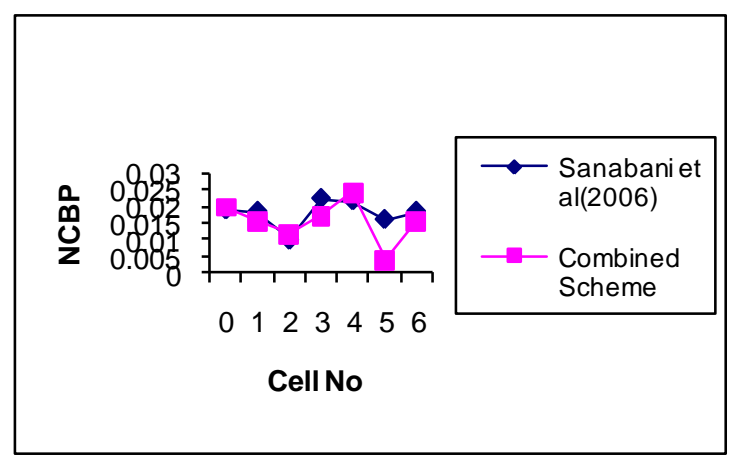

Fig 6(a): New Call Blocking Prob. Graphs for $\mathrm{BSC}$, at run 1.

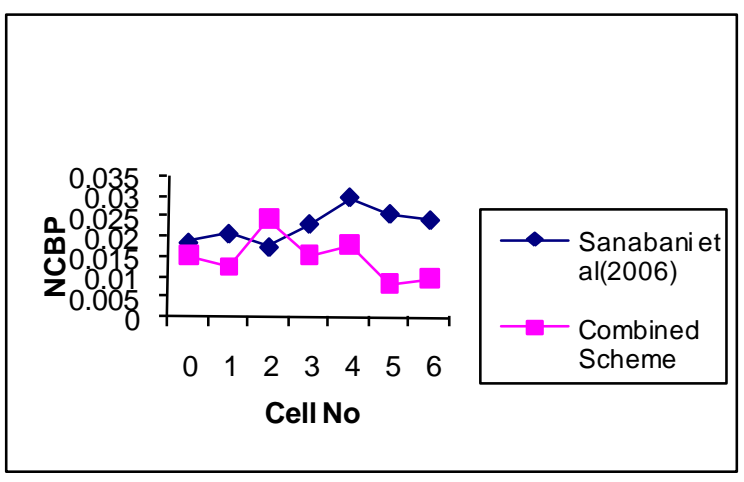

Fig 6(c): New Call Blocking Prob. Graphs for BSC 0, at run 2.

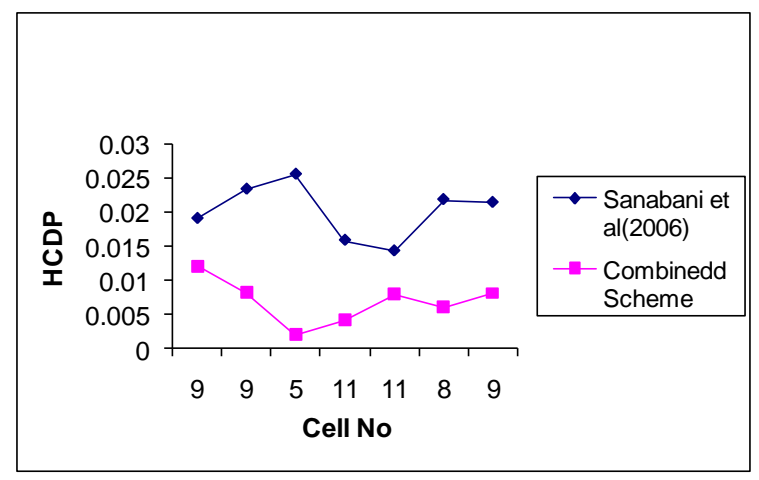

Fig 7(a): Handoff Call Blocking Probability

Graphs for BSC 0 at run 1.

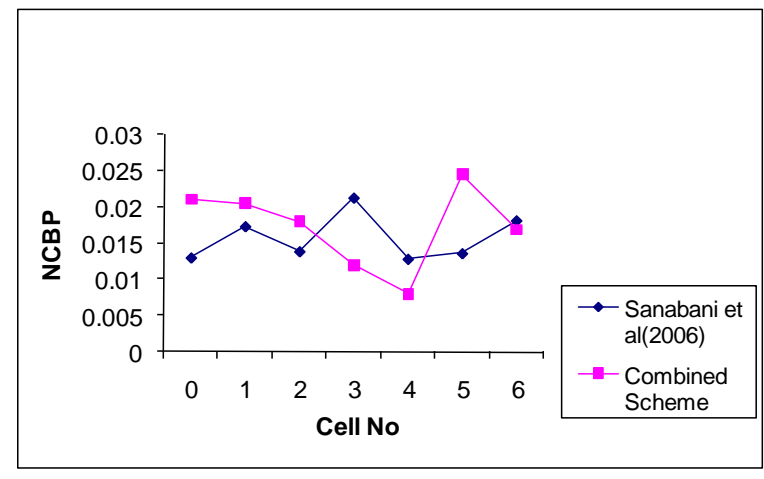

Fig 6(b): New Call Blocking Probability Graphs for BSC 1 at run 1.

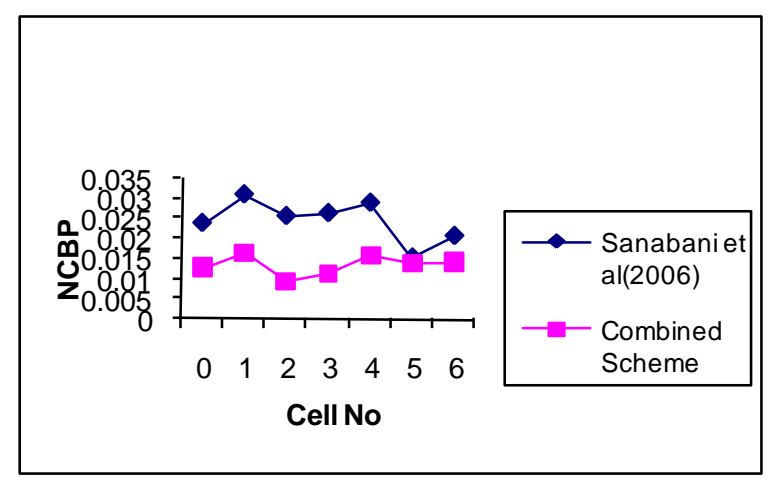

Fig 6(d): New Call Blocking Prob.

Graphs for BSC 1 at run 2.

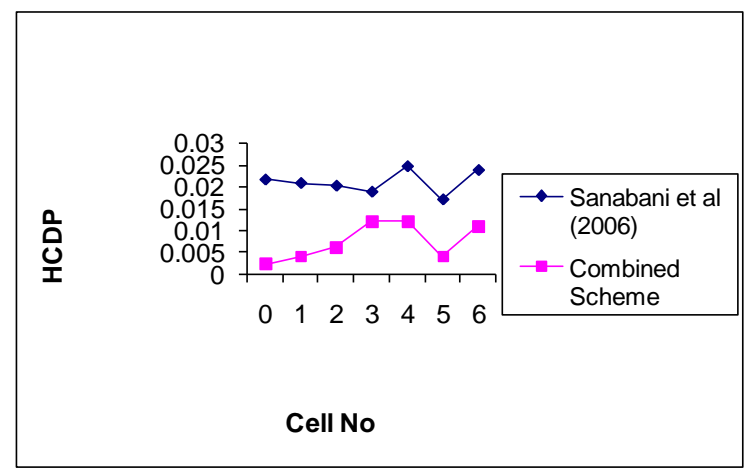

Fig 7(b): Handoff Call Blocking Probability Graphs for BSC 1 at run 1. 


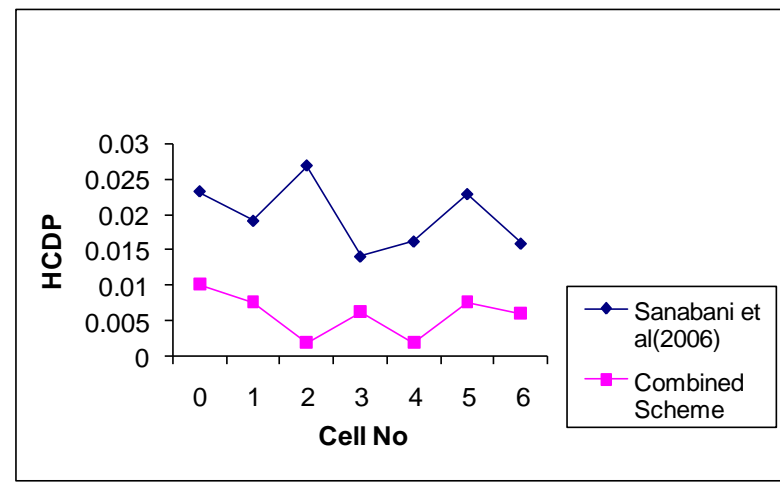

Fig 7(c): Hand off Call Blocking Probability

Graphs for BSC 0 at run 2.

In addition to the fact that the two call level factors of NCBP and HCDP had been further minimized by the combined scheme, it also satisfied the three requirements of a congestion control algorithm, namely: robustness, fairness and reaction time, as noted in [25].

The combined scheme satisfied the requirement of 'reaction time' because it quickly reacts to overload condition using its DegradeBW component of the algorithm to adjust the network system condition. It is however robust due to the fact that it keeps the network system in control for a long time with fewer numbers of calls dropped. This directly shows an increase in the efficiency of the system and further stabilizes the network performance. The scheme also maintain fairness to all calls used as load element in the sense that priority is given to the ongoing calls (most importantly the handoff calls) over the newly established calls which are yet to enter the system.

\section{CONCLUSION AND FUTURE WORKS}

This paper proposes a combined scheme which uses a load balancing strategy to aid an efficient adaptive call admission control scheme. The better performance exhibited by the combined scheme when compared to the CAC only scheme is a clear evidence that the addition of the load balancing strategy had further strengthened the adaptive CAC. This has reduced the value obtained in the NCBP and HCDP significantly. This work can be further enhanced by extending it to calls processing in the cells in other BSC areas in a Mobile Switching Centre (MSC) area. Also the network in focus is homogeneous and an extension of this work can be made for heterogeneous networks.

\section{ACKNOWLEDGEMENTS}

We acknowledge the efforts of Mr. Tunde Enilolobo of Globacom Nigeria Limited Victoria Island Lagos in getting the life data used for this research work and Dr. Adebayo G. A. of the department of Physics, University of Agriculture, Abeokuta Nigeria for his useful suggestions during the period of the research.

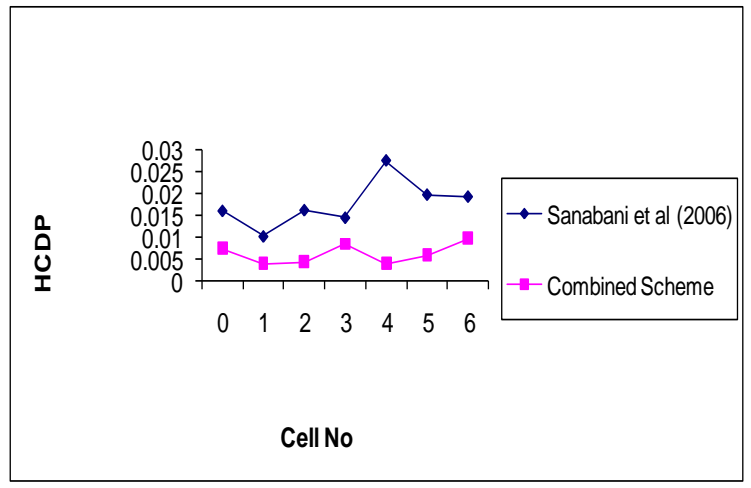

Fig 7(d): Hand off Call Blocking Prob. Graphs

for BSC 1 at run 2.

\section{REFERENCES}

[1] GSMA 2010. The World GSM Coverage map. Available at www.gsmworld.com/roaming/GSM_WorldPoster2010 A.pdf. Accessed on 20th August, 2010.

[2] Rappaport, T. S. 1996. Wireless Communications: Principles and Practice. Upper Saddle River, N. J. London. Prentice Hall PTR, Prentice Hall International.

[3] Narayannan, L. 2002. Channel Assignment and Graph Multicoloring. In Handbook of Wireless Communications and Mobile Computing. Pp $71-94$.

[4] Wireless Networks Spring. 2005. Available at www.ccs.neu.edu/home/rraj/courses/G250/.../CellularNet works.ppt. Accessed on 19th October, 2008.

[5] Ayeni, J. O. A. 1992. Fundamentals of Computing. University of Lagos Press, Akoka, Lagos.

[6] Tanenbaum, A. S. 2001. Modern Operating Systems, 2nd Edition, Prentice Hall Inc., Upper Saddle River, New Jersey.

[7] Zuikevicuite, V. and Pedone, F. 2008. Conflict-Aware Load-Balancing Techniques for Database Replication. SAC'08. Fortaleza, Ceara, Brazil.

[8] Mcmillen, C., Stubbs, K., Rybski, P. E., Stoeter, S. A., Gini, M., and Papanikolopoulos, N. 2002. Resource Schedulling and Load Balancing in Distributed Robotic Control Systems. Available at www.colinm.org/papers/McMillen-2002-IAS-final.pdf. Accessed on 10th September, 2008.

[9] Aversa, L. and Bestavros, A. 1999. Load Balancing a Cluster of Web Servers. Available at www.cs.bu.edu/techreports/1999-001-dpr-cluster-loadbalancing.pdf 
[10] Nehra, J., Patel, R. B., and Bhat, V. K. 2007. A Framework for Distributed Dynamic Load Balancing in Heterogeneous Cluster. Journal of Computer Science, Vol. 3, No. 1, Pp. $14-24$.

[11] Johansson, H. and Steensland, J. 2006. A Performance Characteristics of Load Balancing Algorithms for Parallel SAMR Applications. Available at: www.it.uu.se/research/publications/lic/2006010/paperC.pdf. Accessed on 20th August, 2008

[12] Zhang, H. 2008. On Load Balancing Model for Cluster Computers. International Journal of Computer Science and Network Security. Vol. 8, No. 10, pp. $263-269$.

[13] Fang, X. and Ghosal, D. 2003. Analysing Packet Delay Across A GSM/GPRS Network. Available at www.cs.ucdavis.edu/research/tech-report/2003/CSE2003-3.pdf Accessed on 10th September, 2008.

[14] Du, L., Bigham, J. and Cuthbert, L. 2004. A Bubble Oscillation Algorithm for Distributed Geographic Load Balancing in Mobile Networks. IEEE INFOCOM 2004.

[15] Megha, G. and Sachan, A. 2007. Distributed Dynamic Channel Allocation Algorithm for Cellular Mobile Network. Journal of Theoretical and Applied Information Technology. Vol. 16, No 2, pp. $58-63$.

[16] Smys, S. and Bala, G. J. 2009. K-connection Maintenance algorithm for Balanced Routing in Mobile Ad Hoc Networks. International Journal of Computer Networks and Communications (IJCNC). Vol. 1, No 3, pp. 105 111.

[17] Jain, P. and Gupta, D. 2009. An Algorithm for Dynamic Load Balancing in Distributed Systems with Multiple Supporting Nodes by Exploiting the Interrupt Service. International Journal of Recent Trends in Engineering. Vol. 1, No. 1, pp. 232 - 236. Academy Publisher.

[18] Rachida, A., Mustapha L., AbdelAziz, M. Z., Malika, B., and Mehammed, D. 2009. Load Balancing: An Approach Based on Clustering in Ad Hoc Networks. Journal of Computing and Information Technology - CIT. Vol. 17, No 2, pp. 177 - 184.

[19] Chhabra, A., Singh, G., Waraich, S.S., Sidhu, B., and Kumar, G. 2006. Qualitative Parametric Comparison of Load Balancing Algorithms in Parallel and Distributed Computing Environment. Proceedings of World Academy of Science, Engineering and Technology (PWASET). Vol. 16, Pp. 39-42. Available at www.waset.org/journals/waset/v16/v16-8.pdf.

[20] Mileff, P. and Nehez, K. 2005. Fuzzy Based Load Balancing for J2EE Applications. Production Systems and Information Engineering. Vol 3. Pp. Available at http://alpha.iit.unimiskolc.hu/publications/pubs/2005c.pdf

[21] Bustos-Jimenez, J., Caromel, D., and Piquer, J. M. 2006. Load Balancing: Towards the Infinite Network. A CoreGrid Technical Report Number TR-0049. Available http://www.coregrid.net/mambo/images/stories/Technical Reports/tr-0049.pdf. Accessed on 10th May, 2008.
[22] Karger, D. R. and Ruhl, M. 2004. Simple Efficient Load Balancing algorithms for Peer-to-Peer Systems. Available at www.iptps04.cs.ucsd.edu/papers/karger- loadbalance.pdf. Accessed on $25^{\text {th }}$ August, 2008.

[23] Ali, A. and Belal, M. A. 2007. Multiple Ant Colonies Optimization for Load Balancing in Distributed Systems. ICTA '07 Hammamet, Tunisia.

[24] Visalakshi, P. and Sivanandam, S. N. 2009. Dynamic Task Scheduling with Load Balancing using Hybrid Particle Swarm Optimization. International Journal of Open Problems in Computing and Mathematics. Vol. 2, No 3, pp. $475-488$.

[25] Karagiannis, G. 2002. Scalability and Congestion Control in Broadband Intelligent and Mobile Networks. A Ph. D. Dissertation submitted to the Centre of Telematics and Information Technology, University of Twente.

[26] Peha, J. M. 1997. Scheduling and Admission Control for Integrated Services Networks: The Priority Token Bank.

[27] Hou, J., Yang, J., and Papavassiliou, S. 2002. Integration of Pricing with Call Admission Control to Meet QoS Refinement in Cellular Networks. IEEE Transactions on Parallel and Distributed Systems, Vol. 13, No 9, pp. 898 910.

[28] Fang, Y. and Zhang, Y. 2002. Call Admission Control Schemes and Performance Analysis in Wireless Mobile Networks. IEEE Transactions on Vehicular Technology, Vol. 51, No 2, Pp. $371-382$.

[29] Nasser, N. and Hussanein, H. 2004. Combined Admission Control Algorithm and Bandwidth Adaptation Algorithm in Multimedia Cellular Networks for QoS Provisioning. IEEE. Pp 1183 - 1186.

[30] Oyebisi,, T. O. and Ojesanmi, O. A. 2005. Development of Congestion Control Scheme for Wireless Mobile Network. Journal of Theoretical and Applied Information Technology. Pp. 966 - 972.

[31] Sanabani, M., Shamala, S., Othman, M., and Desa, J. 2006. Adaptive Call Admission Control for Prioritized Adaptive Services in Wireless/Mobile Multimedia Cellular Networks. IJCSNS, International Journal of Computer Science and Network Security. Vol. 6, No. 3B, pp. $114-124$

[32] Wu, B. Y. and Chao, K-M 2004. Spanning Trees and Optimization Problems. CRC Press Company. Chapman $\&$ Hall/CRC. New York. 